\title{
Green Manufacturing of Ammunition through Knowledge Management with Distributed Access
}

\author{
Ali H. Dogru , Murat M. Tanik ${ }^{* *}$, Franz Kurfess, Marcus Healey, Leon Jololian \\ New Jersey Institute of Technology
}

This paper describes a distributed software requirements gathering methodology dealing with knowledge management for environmentally safer production and lifecycles aspects of tank ammunition. A requirements elicitation methodology is adapted and implemented as a distributed-access tool on the Internet. This tool is used for gathering the requirements-related information for a specific ammunition production process. During product development, requirements negotiation is the process where the customer needs are identified. This process is

\section{Introduction}

Requirements negotiation is an iterative process where, through reflection and experience, users become familiar with the technology and developers become familiar with the user needs [HERLEA 97]. To produce quality products, understanding of requirements for a software system is a major concern. Requirements engineering is a common terminology used to specify various requirements-related activities. Requirements engineering comprises four specific processes [RAGHAVAN 94]:

1. Requirements elicitation - The process through which customers, buyers, or users of a software system discover, reveal, articulate, and understand their requirements. Experience over the last 30 years shows that incorrect, incomplete, or misunderstood requirements are the most common causes of poor quality, cost overruns, and late delivery of software regarded as one of the most important parts of building a system because during this stage it is decided precisely what will be built. The concept has been extended from software-centered systems to manufacturing processes, and also towards higher-level concerns such as environmental awareness to be represented in the requirements of the product or system. The knowledge about what to build develops and evolves as a result of a collaborative requirement entry by different types of users and developers.

systems in particular, and complex systems in general.

2. Requirements analysis - The process of reasoning about the requirements that have been elicited; it involves activities such as examining requirements for conflicts or inconsistencies, combining related requirements, and identifying missing requirements.

3. Requirements specification - The process of recording the requirements in one or more forms, including natural language and formal, symbolic, or graphical representations; also, the product that is the document produced by that process.

4. Requirement validations - The process of confirming with the customer or user of the system that the specific requirements are valid, correct and complete.

To develop high quality complex systems, the requirements elicitation process is an essential activity in the overall system development task.

\footnotetext{
* Affiliated with the Middle East Technical University, Ankara, Turkey

** Affiliated with the University of Alabama at Birmingham
} 
A framework to illustrate these requirements was developed by Michael Christel and Kyo Kang, members of the Software Engineering Institute (SEI), located at Carnegie Mellon University in Pittsburgh [MILLER 93]. The requirement elicitation process model consists of the following phases:

1. Fact-Finding Phase: This process allows an examination of the organization into which the target system will be placed. It develops high level statements of the system's missions and roles, determines constraints on the architecture of the system's mission and roles, determines constraints on the architecture, and identifies the existence of similar systems [CHRISTEL 92].

2. Requirement Gathering and Classification: This phase allows the gathering and organizing of information with the help of multiple views that express the information that is to be built.

3. Evaluation and Rationalization: This phase is responsible for exposing inconsistencies in the gathered requirements and determining why the information has been expressed as a requirement.

4. Prioritization: This phase determines the relative importance of each requirement and the relative order of the requirements.

5. Integration and Validation: This phase combines all the information acquired in the preceding phases and creates a set of requirements. Validation is performed to determine that the requirements meet the goals and objectives outlined during the fact-finding stage.

\section{Knowledge Management}

Knowledge management entails formally managing knowledge resources in order to facilitate access and reuse of knowledge, typically by using advanced information technology. A wide range of technologies are used to implement knowledge management systems: e-mail, databases and data warehouses, group support systems, browsers and search engines, internets and intranets, expert and knowledge-based systems, and intelligent agents [DANIEL 98].

Historically knowledge has been stored on papers and in people's minds. Such a storage method leads to inefficient management of knowledge, as it is extremely difficult to maintain and update. Storing data in knowledge warehouses and knowledge bases greatly improves the management, maintenance and updating of data. Moreover, data stored in such a form can be made more widely accessible.

It is also absolutely necessary for the user as well as the developers to understand the environment in which the system is supposed to function. The requirements must be specified such that the system can easily be integrated into the other existing systems. The lack of domain knowledge accessible by the user or developer can lead to improper knowledge management.

Cooperative work systems such as World Wide Web and Lotus Notes are beginning to tackle the aspect of knowledge management. Database systems can contribute much of the required functionality. Hence it is required to integrate functionality and ideas from these sources. With the Web and the use of search engines, many people are already experiencing significant changes in how they use and manage knowledge [SKUCE 97].

\section{Environmental Life Cycle}

A primary thrust of industrial ecology is that manufacturers practice product stewardship designing, building, maintaining, and recycling products in such a way that they pose minimal impact to the wider world. The way in which these tasks are addressed in a formal manner is through Life-Cycle Assessment (LCA), a family of methods for looking at materials, services, 
products, processes, and technologies over their entire life [GRAEDEL 95].

The essence of life-cycle assessment is the evaluation of the relevant environmental, economic, and technological implications of a material, process, or product across its lifespan from creation to waste or, preferably, to re-creation in the same or another useful form.

LCA consists of three stages: inventory analysis, impact analysis, and improvement analysis. First, the scope of LCA is defined. An inventory and impact analysis are then performed, the result being an environmentally responsible product rating $\left(\mathrm{R}_{\mathrm{ERP}}\right)$. This rating guides an analysis of potential improvements (which may fed back to influence the inventory analysis). Finally, the improved product is released for manufacture.

\section{Knowledge Representation}

Knowledge representation can be done in many ways. The knowledge management systems represent knowledge in both human- and machine-readable forms. Human-readable knowledge is typically accessed using browsers or intelligent search agents. But some knowledge is accessible for machine-readable purposes, designed as an expert system's knowledge base to support decision making [DANIEL 98].

\section{Searching for Knowledge}

Knowledge search is a very wide concept that encompasses various search techniques. A few of them are:

- Search Engines: It is one of the most widely used modes of searching on the web. A wide range of well-known internet search engines - like AltaVista, Excite, Infoseek, Lycos, WebCrawler, and Yahoo have been used to guide users to locate information on the Internet. These and other search engines can be adapted to
Intranet environments for knowledge management [DANIEL 98].

- Intelligent agents: Intelligent agents are used to connect people to information available on the Internet or Intranets. Heuristics can be used to gather additional insights into a user's interests. Based on syntactical aspects, attempts can be made to determine significant phrases that provide insight into user goals.

\section{SEI Requirements Engineering Framework}

Requirements engineering is a disciplined application of scientific principles and techniques for developing, communicating and managing requirements. Requirements elicitation normally involves several developers (the requirements analysts and software engineers) and several customers (the buyers or users of the software). Each of these persons brings different knowledge and skills to the effort [RAGHAVAN 94].

The requirements elicitation process focuses on addressing, supporting, and facilitating the learning cycles involved with the evolution of the requirements. The system evolves through activities of users and developers, who in turn gain enhanced understanding of the system through that. It is especially useful when there are requirements articulation problems, and it is helpful in overcoming some of the technical issues of requirements elicitation for the evolution of complex and incomplete systems.

\section{Requirements Elicitation Framework}

Rzepka decomposes the requirements engineering process into three activities [Rzepka 89]:

1. Elicit requirements from various individual sources,

2. Insure that the needs of all users are consistent and feasible and

3. Validate that the requirements so derived are an accurate reflection of user needs. 
Elicitation will likely iterate through these activities during requirements development. Previously, the requirements elicitation process consisted of scattered processes, methodologies and techniques, each having their own benefits, strengths, and weaknesses. By themselves, none of these strategies were able to address all the attributes necessary to produce a quality set of requirements that met the needs of the stakeholder community. Existing models, methodologies, and techniques failed to address the problems inherent in the requirements elicitation activity, namely: system scope, understanding among participants of the process, understanding among personnel affected by the process, and a recognition of the volatility of requirements [MILLER 93].

In an effort to address these issues, the SEI framework was established. It is composed of a process model, a methodology, and a group of supporting techniques. The process model guides the methodology and techniques imposed by the framework. A methodology is a fine-grained activity that supports a process.

\section{Requirements Elicitation Process Model}

The communication between the user-oriented and developer-oriented activities is cyclical, and enhanced via modeling. The representation of the requirements should promote mutual understanding while allowing for inevitable change, and hence this representation should be introduced as early into the requirements engineering process as possible while still maintaining the desirable characteristics of modifiability, readability, and analyzability [CHRISTEL 92]. Figure 1 gives an overview of the requirements elicitation process model.

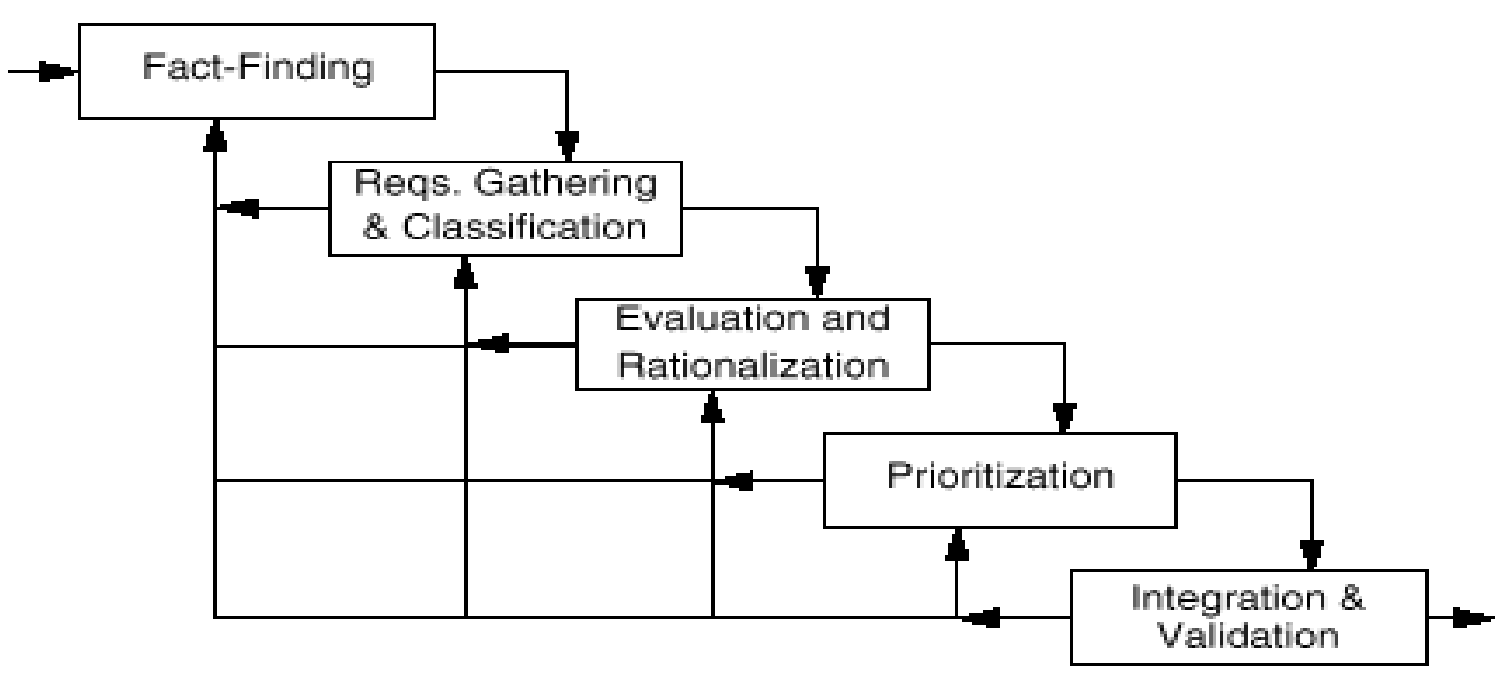

Figure 1 Requirement Elicitation Process Model [CHRISTEL 92].

This elicitation process model is first executed during the concept exploration phase of system development, which is initiated after the creation of a mission statement. Following this phase, the first level of detail in the requirements specification is achieved. During the subsequent demonstration and validation phase, these specifications are checked, unclear requirements clarified, unknown requirements identified, and the existing ones refined as necessary. These elicitation steps are then cycled through, beginning with "requirements 
gathering" to detail and improve the requirements document. The demonstration and validation phase is entered with incomplete requirements, and therefore these elicitation process steps are revisited after the first pass through the concept exploration phase [CHRISTEL 92].

With regard to the user community, factfinding begins with identifying the relevant parties at multiple levels within the community, e.g. from a high-level commander for a strategic long term perspective to an end user for the immediate perspective. The operational context and problem context are defined, perhaps through goal trees and mission statements, which help with the later filtering of the requirements. This includes an objectives analysis, which studies the user organization's objectives, constraints against full achievement of the objectives, and their influences and interactions. Context analysis and the determination of operational modes and mission scenarios complete the user-oriented task fact-finding activities. The developer oriented fact-finding tasks are performed in parallel.

\section{Ammunition Manufacturing and REPI}

To explain the use of this system, use the manufacturing process of 120MM M829E3 tank ammunition. This system is thus used to perform the requirements analysis for the environmental lifecycle simulation model.

\section{MM M829E3 Ammunition}

120MM M829E3 [DoD] is an armor piercing shell fired by a tank. It is manufactured under the auspices of the US Department of Defense. The ammunition is composed of subparts that are combined together during manufacturing. Each manufacturing phase undergoes rigorous testing. The various components of $120 \mathrm{MM}$ M829E3 are listed in Table 1, and pictured in Figure 2.

\begin{tabular}{|l|l|l|l|l|}
\hline PENETRATOR & IGNITER & COMPOSITE & \multicolumn{2}{|c|}{ PROPELLANT - 3 } \\
\hline $\begin{array}{l}\text { Depleted } \\
\text { Uranium Wastes }\end{array}$ & $\begin{array}{l}\text { Black } \\
\text { Powder }\end{array}$ & Carbon Fiber & Acetic Acid & Diethyl phthalate \\
\hline $\begin{array}{l}\text { Low level } \\
\text { Wadioactive }\end{array}$ & (QA Tests) & $\begin{array}{l}\text { Scrap } \\
\text { Composite }\end{array}$ & Nitric Acid & RDX/HMX \\
\hline WSC & Lead & Sulfuric Acid & Acetic Anhydride & $\begin{array}{l}\text { DEGDN/BTTN/ } \\
\text { NG/ } \\
\text { TEGDN }\end{array}$ \\
\hline & Carbon & Water Soluble & $\begin{array}{l}\text { Nitrocellulose } \\
\text { Cines }\end{array}$ & $\begin{array}{l}\text { Dimethyl } \\
\text { Formamide }\end{array}$ \\
\hline & & & Cyclohexone & Sulfuric Acid \\
\hline & & & Nox & \\
\hline
\end{tabular}




\begin{tabular}{|l|l|l|l|l|}
\hline BASE CASE & TRACER & FIN & PACKAGING & PRIMER \\
\hline Steel Turning & Barium Sulfate & $\begin{array}{l}\text { Water Soluble } \\
\text { Coolants }\end{array}$ & Pallet & $\begin{array}{l}\text { Lead } \\
\text { Thiocyanate }\end{array}$ \\
\hline Solid Rubber & $\begin{array}{l}\text { Barium Peroxide } \\
\text { Igniter }\end{array}$ & & CARC Paint & $\begin{array}{l}\text { Potassium } \\
\text { Chlorate }\end{array}$ \\
\hline $\begin{array}{l}\text { Water Soluble } \\
\text { Coolants (WSC) }\end{array}$ & Hydrogen Fluoride & & $\begin{array}{l}\text { Benite or } \\
\text { Black Powder }\end{array}$ \\
\hline Phosphate Sludge & Combustion Prod. & & & \\
\hline
\end{tabular}

Table 1. Ammunition components and material

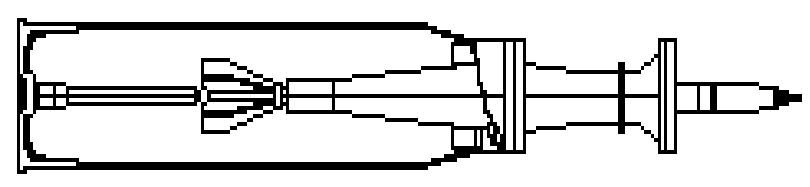

Figure 2 120MM M829E3

Ammunition

\section{Ammunition Manufacturing Process}

All the materials required for the manufacturing of the 120MM M829E3 are shipped form external sources either by rail or road. The process is composed of the following tasks:

- Testing of accumulated material

- Assembly

- Coating

- Weight verification and chambergage

- Leak test and shipment

\section{MM M829E3 Specification in REPI}

The following sections describe the mapping of the manufacturing of 120MM M829E3 cartridge into the different phases of the requirement elicitation process, which has two main parts:

- User menu and

- Developer menu.

Each of the two parts is described using the five different phases of requirement elicitation from the previous sections:

- Fact-finding.

- Gathering and classification.

- Evaluation and rationalization.

- Prioritization and planning.

Integration and validation.

\section{User Menu}

In this menu, the users describe their requirements with respect to the system domain. The users' personal information and project related information is stored in the databases. 


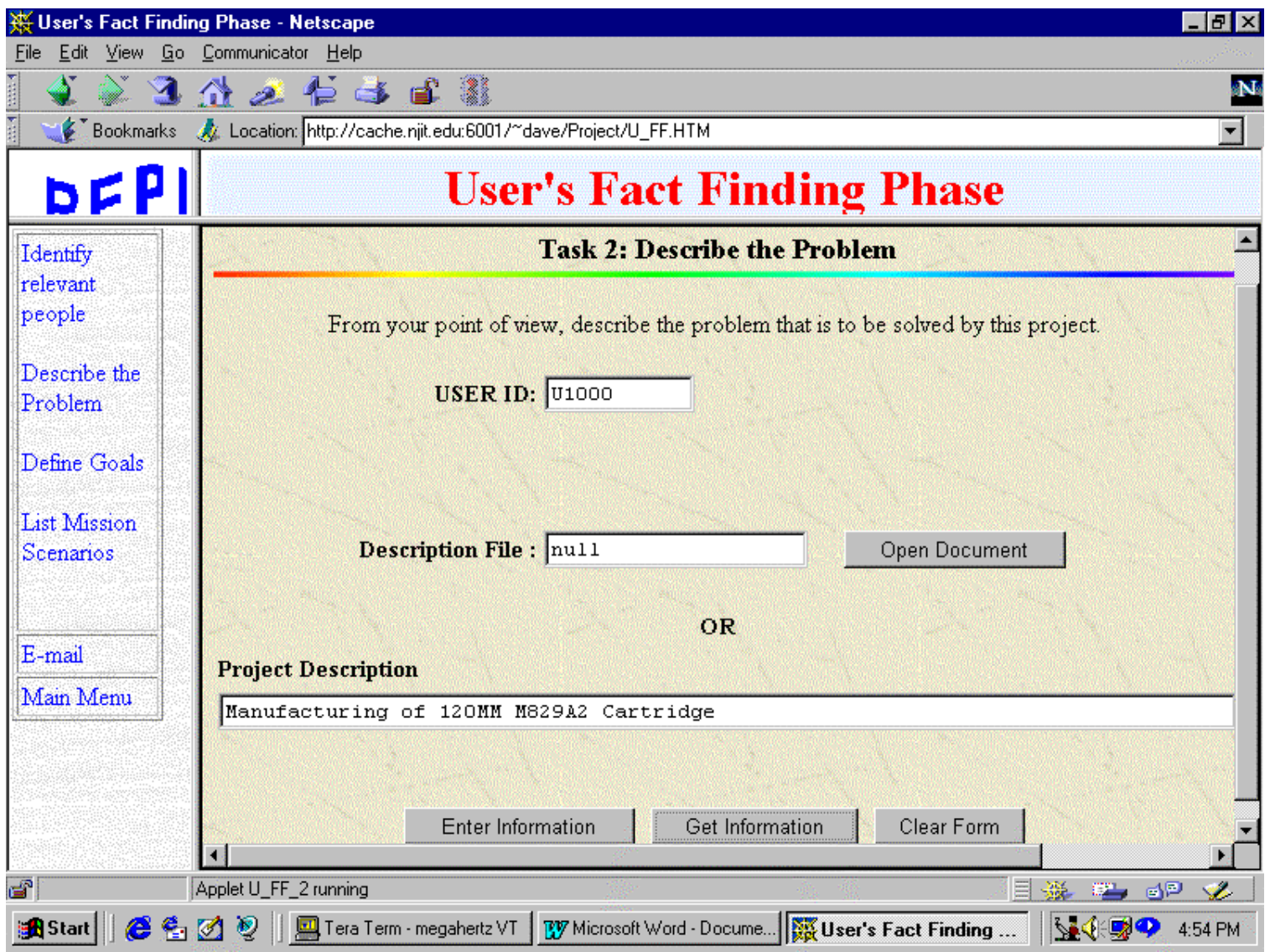

Figure 3 Describe the problem

\section{Fact Finding}

This phase has the following sub-sections:

1. Identify relevant people. People from the military who have requested for the manufacturing of the ammunition insert their personal information in this form. Information like their name, telephone number, email and their category are specified.

2. Describe the problem. Here the user specifies the problem under consideration. The problem specification in this case is the manufacturing of the ammunition. Related screen is depicted in Figure 3.

3. Define goals. In this screen, the user specifies the various objectives of the system. In the manufacturing of $120 \mathrm{MM}$
M829E3 ammunition, the various goals could be

- Receive materials from external sources.

- Testing of each process.

- Assembly of gathered material.

- Applying of coats of paint to different components.

- Verification of weight.

- Shipment of the manufactured ammunition.

4. List mission scenarios. Each goal has many missions to accomplish. This screen allows the user to enter the different scenarios that are related to a particular goal. 


\section{Gathering and Classification}

In this phase the user is allowed to specify needs to the developer. This phase has the following sub-sections:

- Add requirements

- List requirements.
To view the requirements that a particular user or any other user has listed, this screen is activated. Here the listing can be done on user basis or all the listing can be done.

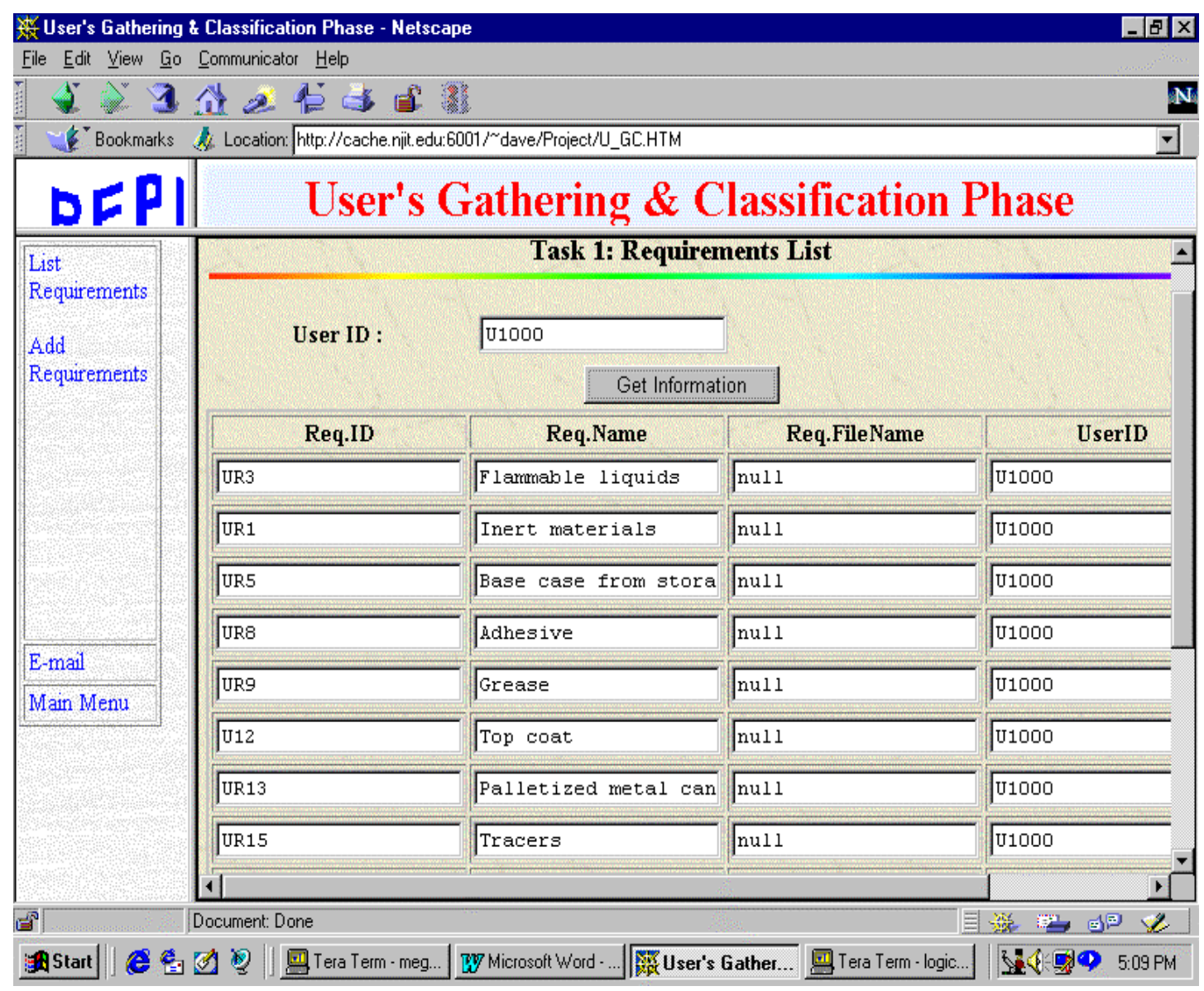

Figure 4 Requirements list

\section{Evaluation and Rationalization}

The user evaluates his requirements on basis on the necessity of the requirement. This phase consists of two sub-parts:

- Perform abstraction. The user in this screen mentions the reason why the requirement is valid and necessary.

- Capture rationale. The user explains the reason for the requirement from his view point.

\section{Prioritization and Planning}

All the requirements are prioritized depending on their importance level, understanding and priority. The user specifies these three levels for each of the requirements that he has specified.

\section{Integration and Validation}

This phase is divided into two parts: 
- Validate requirement. In this screen the user confirms his requirement against the goal that he has specified.

- Obtain authorization. An authorized person authorizes the requirements specified by the user

\section{Developer Menu}

The developer's perspective towards the project is specified in the menus in this section. The phases are similar to the ones in the users menu.

\section{Fact Finding}

This phase consists of:

- Identify domain experts.

- Identify domain models.

- Conduct technological survey.

- Assess constraints.

\section{Gathering and Classification}

This phase is composed of:

- Add requirements.

- List requirements.

- Classify requirements.

This is an additional screen as compared to users menu. Here the requirements can be listed based on their category.

\section{Evaluation and Rationalization}

The requirements specified by the developer can be evaluated and rationalized in this phase. It consists of:

- Risk assessment. The risk involved in a particular requirement can be stated at this point. The risk could be in terms of machinery usage, hardware, manpower etc.

- Feasibility analysis. Specify the feasibility of the requirement with respect to the manufacturing of the ammunition.

- Cost/Benefit analysis. Analyze and state the cost and the benefit related to the particular requirement.

\section{Prioritization and Planning}

The requirements specified need to be prioritized for decision making. This phase is made of:

- Prioritize requirements. Requirements specified by the developer are prioritized based on cost, dependence level and priority.

- Plan incremental development stages. This screen list all the requirements specified by the user and developer with the priorities based on different criteria.

\section{Integration and Validation}

This is the last phase of requirement engineering. This phase consists of only one sub-section, resolved requirements, which list all the resolved requirements from the user and developer's menu so that they can be considered in the next phase of software engineering.

\section{Conclusions and Future Work}

"Early defect fixes are typically to orders of magnitude cheaper than late defect fixes, and the early requirements and design defects typically leave more serious operational consequences" [CHRISTEL 92]. The requirements elicitation process aids the people in the army to specify their requirements in a more systematic manner. The objective of mapping the requirements elicitation process with the environment are:

- Proper, precise and accurate specification of materials required for the manufacturing of the ammunition.

- Specification of the effects of the manufacturing process on the environment, for example, the effect of cost, chemicals used in the production etc.

- Proper communication between the people at the site of manufacturing and the army personnel who request for the ammunition production.

To improve the decision making process, a mechanism internal to the system that can generate its own decisions has to be incorporated. This can be achieved with the help of an expert system, for example. 
The requirements elicitation process can be used to specify requirements for all areas of the environmental life cycle model, namely, Design, Production, Distribution, Packaging and Demanufacturing. This initial implementation of REPI lacks many features, a very important one being the security related capabilities. Currently we are in the progress of enhancing this implementation.

\section{Acknowledgements}

This work is supported by the U.S. Department of Defense through the Sustainable Green Manufacturing Initiative at NJIT under the guidance of Dr. Daniel Watts from the Center of Environmental Engineering Science.

The implementation work described in this paper has been performed by the following students over the last two years: Deepak Pandit, Mariam Burmawalla, and Umang Dave. Without their dedication and hard work, REPI and its use for the Sustainable Green Manufacturing Initiative would not have been possible.

\section{References}

[CHRISTEL 92] Christel, Michael G. and Kang, Kyo C. "Issues in Requirement Elicitation.", Technical Report CNW/SEI-02-TR-12 or ESC-TR-92-012. Software Engineering Institute, Carnegie Mellon University, Pittsburgh PA. September 1992, http://www.sei.cmu.edu/publications/documents/92.re ports/92.tr.012.html (20 July, 1998)

[DANIEL 98] Daniel E. O'Leary. "Enterprise Knowledge Management", IEEE Computer, pp. 5461, March 1998.

[DoD] (http://www.pica.army.mil/orgs/ccac/cch/ccha.html)

[GRAEDEL 95] T. E. Graedel, B. R- Allenby. Industrial Ecology, Prentice Hall, Englewood Cliffs, New Jersey 07632. 1995.

[HERLEA 97] Herlea, Daniela. "Knowledge Management for Requirement Engineering", AAAI Spring Symposium, Artificial Intelligence in Knowledge Management Stanford University. March 24-26, 1997.

[MILLER 93] Miller, U Greg and Tanik, Murat M. "Multimedia Applications in Software Engineering",
Technical report 93-CSE-50. Southern Methodist University, Dallas, Texas. November 1993.

[ORACLE 96] "Oracle Intranet Strategy", An Oracle White Paper. Oracle Corporation, Redwood Shores, CA- July 1996.

http://www.oracle.com/promotions/intranet/html/intr ane_wp.html (14 Feb, 1998)

[RAGHAVAN 94] Raghaven, Sridhar, Zelesnik, Gregory, and Ford, Gray. Lecture Notes on "Requirements Elicitation", Report CMU/SEI-94EM-10. Software Engineering Institute, Carnegie Melon University, Pittsburgh PA. 1994. http://www.sei.cmu.edu/publications/documents/ems/ 94.em.010.html (25 July, 1998).

[RZEPKA 89] Rzepka, William E. "A Requirements Engineering Testbed: Concept, Status, and First Results". In Bruce D. Shriver (editor), Proceedings of the Twenty-Second Annual Hawaii International Conference on System Sciences, 339-347. IEEE Computer Society, 1989.

[SKUCE 97] Skuce, Doug. "Hybrid KM: Integrating Documents, Knowledge Bases, Databases, and the Web", AAAI Spring Symposium, Artificial Intelligence in Knowledge Management Stanford University. March 24-26, 1997.

http://ksi.cpsc.ucalgary.ca:80/AIKM97/skuce/skuce.h tml 